\title{
Differential predictors of pain and disability in patients with whiplash injuries
}

\author{
Michael JL Sullivan $\mathrm{PhD}^{1}$, William Stanish $\mathrm{MD}^{2}$, Maureen E Sullivan $\mathrm{PhD}^{3}$, \\ Dean Tripp $\mathrm{PhD}^{4}$
}

MJL Sullivan, W Stanish, ME Sullivan, D Tripp. Differential predictors of pain and disability in patients with whiplash injuries. Pain Res Manage 2002;7(2):68-74.

The psychological predictors of pain and disability were examined in a sample of people who sustained whiplash injuries during rear-end motor vehicle accidents. Sixty-five patients referred to a specialty pain clinic with a diagnosis of whiplash injury completed measures of depression, anxiety, catastrophizing, pain and perceived disability. Regression analysis revealed that psychological variables accounted for $18 \%$ of the variance in pain ratings. The magnification subscale of the Pain Catastrophizing Scale was the only variable that contributed significant, unique variance to the prediction of pain. Psychological variables accounted for 37\% of the variance in perceived disability scores. In the latter analysis, however, none of the independent variables contributed significant, unique variance to the prediction of perceived disability. Psychological variables accounted for significant variance in disability ratings, even when controlling for pain intensity. Discussion focuses on the need to draw clearer distinctions between determinants of pain and disability, and directions for interventions aimed at minimizing disability following whiplash injury are suggested.

Key Words: Catastrophizing; Depression; Disability; Pain; Whiplash

\section{Les prédicteurs différentiels de la douleur et de l'invalidité chez les patients présentant un coup de fouet cervical}

\begin{abstract}
RÉSUMÉ : Les prédicteurs psychologiques de la douleur et de l'invalidité ont été évalués chez un échantillon de personnes qui ont subi un coup de fouet cervical lors d'un accident d'automobile par l'arrière. Soixante-cinq patients qui ont consulté dans une clinique spécialisée de la douleur par suite d'un diagnostic de coup de fouet cervical ont fourni des données sur la dépression, l'anxiété, la catastrophisation, la douleur et l'incapacité perçue. L'analyse de régression a révélé que les variables psychologiques comptent pour $18 \%$ de la variance dans les évaluations de la douleur. La graduation d'amplification de l'échelle de catastrophisation de la douleur était la seule variable qui fournissait une variance importante et unique pour prédire les indices d'invalidité perçue. Cependant, dans la dernière analyse, aucune des variables indépendantes n'a fourni de telle variance. Les variables psychologiques étaient responsables d'une variance considérable dans les taux d'invalidité, même pour contrôler l'intensité de la douleur. La discussion est axée sur le besoin d'établir des distinctions claires entre les déterminants de la douleur et de l'invalidité, et des orientations d'interventions visant à réduire l'invalidité après un coup de fouet cervical sont proposées.
\end{abstract}

${ }^{1}$ Départment de Psychologie, Université de Montréal, Montréal, Québec; ${ }^{2}$ Department of Surgery, Dalhousie University, and ${ }^{3}$ Fenwick Psychological and Health Consultants, Halifax, Nova Scotia; ${ }^{4}$ Department of Psychology, Queen's University, Kingston, Ontario Correspondence and reprints: Dr Michael Sullivan, Départment de Psychologie, Université de Montréal, CP 6128, Succursale Centre-Ville

Montréal, Québec H3C 3J7. Telephone 514-343-7980, e-mail michael.jl.sullivan@UMontreal.ca Received for publication August 19, 1999. Accepted February 21, 2000 
W hiplash injuries arise from incidents that expose the head and neck to sudden changes in velocity $(1,2)$. Although the precise mechanism by which changes in velocity give rise to whiplash symptoms remains unknown, for a significant proportion of individuals, physical and emotional symptoms of distress may persist for prolonged periods, and contribute to significant disability (3-5). The symptoms of pain, headaches, dizziness, nausea, vertigo, cognitive difficulties, anxiety and depression that are associated with whiplash can be sufficiently intense to interfere with social and occupational functioning $(6,7)$.

Chronic pain and pain-related disability develop in approximately $15 \%$ to $20 \%$ of individuals with whiplash injuries $(7,8)$. To date, it has not been possible to identify injury- or illness-related variables that reliably predict who will or will not follow a chronic course of pain and disability following injury. Thus, attention has been drawn to the examination of the psychological predictors of chronic pain and disability.

\section{THE PSYCHOLOGY OF WHIPLASH}

Over the past decade, there has been considerable research addressing the role of psychological factors in persistent pain disorders such as chronic low back pain (9), rheumatoid arthritis (10), fibromyalgia (11) and headache (12). Although it is beyond the scope of this paper to review the literature in depth, two themes have emerged from investigations conducted to date. First, symptoms of emotional distress such as depression and anxiety may arise as a consequence of the experience of persistent pain and, in turn, contribute to pain and disability (13-15). Second, cognitive variables such as self-efficacy, coping, catastrophizing and beliefs about pain have been shown to attenuate or heighten the pain experience of persistent pain sufferers (16-19).

Although the psychology of pain and disability has been addressed within the context of whiplash disorders, discussions have frequently been more speculative than empirically based (20). For example, it has been suggested that psychological variables related to litigation (eg, litigation neurosis), issues related to secondary gain (eg, absolution of responsibility, medical attention) or unconscious drives (eg, repression, conversion) may be the basis for the high level of distress and disability observed following whiplash injury $(20-22)$. One of the obstacles to progress in this area is that many of the psychological variables implicated as causative of whiplash pain and disability have been poorly defined, impossible to measure or couched within theoretical frameworks that have minimal value for either conceptualizing or treating whiplash injuries. To advance knowledge in this area, it is necessary to bring a more rigorous empirical perspective to identifying psychological risk factors for the pain and disability associated with whiplash.

The primary aim of the present research was to examine the psychological predictors of pain and disability in a sample of individuals who sustained whiplash injuries in rearend motor vehicle accidents. The choice of predictor variables was guided by recent theory and research on the psychology of pain and disability $(19,23,24)$. For example, depression, anxiety and catastrophizing have been discussed as contributors to pain and disability in chronic pain sufferers $(11,19)$.

Although the relation between depression and pain has been studied extensively in the chronic pain literature (15), little is known about the depressive symptomatology associated with whiplash injury. There are indications that patients with whiplash may experience significant depressive symptoms $(6,25)$. However, the relation among depressive symptoms, pain severity and disability in patients with whiplash has received little attention.

Anxiety has also been shown to be associated with the pain experience. Several investigators have suggested that anxiety, fear and avoidance may play significant roles in the distress and disability experienced by patients with chronic pain $(26,27)$. Research findings have been consistent in showing that heightened levels of trait anxiety are associated with a more intense pain experience (28-30).

Catastrophizing has also been discussed as a contributing factor in pain and pain-related disability (9). 'Catastrophizing' is a term that has been used to describe an individual's tendency to focus excessively on pain sensations (ie, rumination), to exaggerate the threat value of pain sensations (ie, magnification) and to feel helpless in decreasing the intensity of pain (ie, helplessness) (31). Level of catastrophizing has been shown to be a predictor of pain and disability in individuals with a variety of persistent pain disorders $(9-12,19)$. Research has shown that the rumination component of catastrophizing is a predictor of disability in patients with chronic pain, even when controlling for pain severity (19). The role of catastrophizing in predicting pain and disability in individuals with whiplash injuries has not yet been examined.

In the present study, patients referred to a specialty pain clinic with a diagnosis of whiplash injury underwent measures of depression, anxiety, catastrophizing, pain and perceived disability. In light of recent discussions suggesting that the determinants of pain may differ from the determinants of disability, predictors of pain and disability were analyzed separately $(19,26)$.

\section{Patients}

\section{PATIENTS AND METHODS}

Sixty-five patients ( 25 men, 40 women) who were referred to the Atlantic Pain Clinic, Halifax, Nova Scotia, participated in the study. Patients were evaluated for suitability to participate in a multidisciplinary pain treatment program. All patients had a diagnosis of whiplash injury, grade I or II, sustained in rear-end motor vehicle accidents. All patients were currently involved in litigation. The mean age of the patients in this sample was 35.2 years $(\mathrm{SD}=7.1$ years). The mean duration of time since their motor vehicle accident was 13 months ( $\mathrm{SD}=12.0$ months).

\section{Procedure and measures}

The patients involved in the study were consecutively referred to the Atlantic Pain Clinic, with whiplash injury 
TABLE 1

Sample characteristics of 65 patients referred to a specialty pain clinic with a diagnosis of whiplash injury

\begin{tabular}{lc}
\hline Variable & Mean \pm SD (range) \\
\hline Age (years) & $35.2 \pm 7.1(24-60)$ \\
Pain duration (months) & $13.0 \pm 12.0(6-36)$ \\
Catastrophizing* & $32.20 \pm 10.91(4-51)$ \\
Depression ${ }^{\star}$ & $20.41 \pm 10.94(3-51)$ \\
Trait anxiety $^{\ddagger}$ & $45.60 \pm 6.32(28-67)$ \\
Pain§ & $37.74 \pm 14.62(9-71)$ \\
Disability & $45.56 \pm 12.53(6-70)$ \\
\hline
\end{tabular}

*Measured by the Pain Catastrophizing Scale; †Measured by the Beck Depression Inventory; $¥$ Measured by the Trait Form of the State-Trait anxiety Inventory; \$Measured by the Pain Rating Index of the McGill Pain Questionnaire; "Measured by the Pain Disability Index

diagnosed according to the criteria of Spitzer et al (7). Analyses were restricted to patients with mild whiplash injuries - grade I or II (neck complaint, with or without musculoskeletal signs, and no objective evidence of fracture, compression or nerve injury). Patients were excluded if they had a diagnosis of another pain-related condition (other than headache) such as fibromyalgia or temporomandibular joint syndrome, if they had been involved in more than one motor vehicle accident in the past two years or if they had undergone surgery.

Patients were asked to complete self-report measures as part of a standard assessment procedure. Approximately one-half of the patients $(n=32)$ were admitted to the program. There were no significant differences in any of the dependent measures between individuals who were admitted and those who were not admitted. Patients did not participate in the program if it was the clinicians' judgement that treatment would not yield significant improvement $(n=6)$, if they had previously participated in a similar program $(n=11)$, if they were unable to attend due to long distance travel $(n=10)$ or if they were unable to secure funding for treatment $(\mathrm{n}=8)$.

Catastrophizing: The Pain Catastrophizing Scale (PCS) (31) is a 13-item self-report measure that assesses three different dimensions of pain-related catastrophic thinking rumination, magnification and helplessness. Patients rate the frequency with which they experience different catastrophic thoughts on a five-point scale with the end points 0 (not at all) and 4 (all the time). In previous studies, the PCS has been shown to have adequate to high internal consistency, with the following coefficient alphas: total 0.87 , rumination 0.87 , magnification 0.66 and helplessness 0.78 (31). The PCS has been shown to be stable over a sixto eight-week period, to correlate with interview methods of assessing catastrophic thinking, and to predict pain and pain behaviour in response to aversive stimulation $(31,32)$.
TABLE 2

Correlations among measures of 65 patients referred to a specialty pain clinic with a diagnosis of whiplash injury

\begin{tabular}{lccccccc}
\hline & Rumin & Magni & Helps & ANX & BDI & PDI & Pain \\
\hline PCST & $0.89^{* *}$ & $0.82^{* *}$ & $96^{* *}$ & 0.12 & $0.55^{* *}$ & $0.55^{* *}$ & $0.30^{* *}$ \\
Rumin & & $0.58^{* *}$ & $0.80^{* *}$ & 0.14 & $0.52^{* *}$ & $0.54^{* *}$ & 0.19 \\
Magni & & & $0.73^{* *}$ & $0.25^{*}$ & $0.45^{* *}$ & $0.44^{* *}$ & $0.42^{* *}$ \\
Helps & & & & $0.02^{* *}$ & $0.50^{* *}$ & $0.51^{* *}$ & $0.25^{*}$ \\
ANX & & & & & $0.32^{* *}$ & 0.15 & 0.00 \\
BDI & & & & & & $0.44^{* *}$ & 0.15 \\
PDI & & & & & & & \\
\hline
\end{tabular}

Pain was measured by the Pain Rating Index of the McGill Pain Questionnaire ${ }^{*} P<0.05$; ${ }^{* *} P<0.01$. ANX Trait Form of the State-Trait anxiety Inventory; BDI Beck Depression Inventory; Helps Helplessness subscale of the Pain Catastrophizing Scale (PCS); Magni Magnification subscale of the PCS, PCST Pain Catastrophizing Scale, Total; PDI Pain Disability Index; Rumin Rumination subscale of the PCS

Depression: The Beck Depression Inventory (BDI) (33) is a 21-item self-report measure of depressive symptomatology. Patients endorse statements that best describe how they have been feeling over the past week. Considerable research supports the reliability and validity of the BDI as a measure of depressive symptomatology in nonclinical and clinical samples $(34,35)$.

Anxiety: The trait form of the State-Trait Anxiety Inventory (STAI-T) (36) is a 20-item self-report measure of dispositional anxiety. Patients rate the frequency of each symptom of anxiety on a four-point scale with the end points 1 (almost never) and 4 (always). Patients' responses are summed to yield a total trait anxiety score.

Pain: The McGill Pain Quesionnaire (37) consists of adjectives describing sensory, affective and evaluative aspects of the pain experience. Patients endorse the adjectives that best describe their current pain. The Pain Rating Index is a weighted sum of all of the adjectives endorsed, and is considered to be one of the more reliable and valid indexes of an individual's pain experience $(10,38)$.

Disability: The Pain Disability Index (39) is a seven-item self-report measure of perceived disability. Patients rate their perceived level of disability for each of seven life domains on a 11-point scale with the end points 0 (no disability) and 10 (total disability). Ratings are summed to produce an overall index of patients' perceptions of their level of disability. Research has shown the Pain Disability Index to be internally reliable and significantly correlated with objective indexes of disability $(40,41)$.

\section{Sample characteristics}

\section{RESULTS}

The means and standard deviations of all measures are presented in Table 1. Measures of catastrophizing, depression, anxiety, pain and disability yielded scores that were comparable with those reported in previous studies of persistent 
TABLE 3

Hierachical regression examining psychological
predictors of pain in 65 patients referred to a specialty
pain clinic with a diagnosis of whiplash injury
\begin{tabular}{llllll}
\hline Variables & Beta & $R^{2}$ & $F($ change) & $P$ & $r$ \\
\hline
\end{tabular}

Step 1

$\begin{array}{lrrrr}\text { Age } & 0.02 & & & 0.05 \\ \text { Sex } & -0.02 & & & -0.03 \\ \text { Pain duration } & -0.05 & 0.01 & 0.3 & 0.82\end{array}$

Step 2

\begin{tabular}{|c|c|c|c|c|c|}
\hline Rumin & 0.03 & & & & 0.19 \\
\hline Magni & $0.55^{\star *}$ & & & & $0.42^{* \star}$ \\
\hline Helps & -0.15 & & & & $0.25^{\star}$ \\
\hline Depression ${ }^{\dagger}$ & -0.05 & & & & 0.09 \\
\hline Trait-anxiety $\ddagger$ & -0.09 & 0.19 & 20.5 & 0.05 & 0.00 \\
\hline
\end{tabular}

${ }^{*} P<0.05 ;{ }^{* *} P<0.01 ;{ }^{\dagger}$ Measured by the Beck Depression Inventory; ${ }^{\ddagger}$ Measured by the Trait Form of the State-Trait anxiety Inventory. Helps Helplessness subscale of the Pain Catastrophizing Scale (PCS); Magni Magnification subscale of the PCS; Rumin Rumination subscale of the PCS

pain sufferers $(19,41,42)$. Sixty-six per cent of the sample scored in the clinical range of depression (BDI score above 15). There were no differences between the sexes on any of the measures.

\section{Correlations among measures}

Table 2 shows the intercorrelations among the independent and dependent variables. The magnification and helplessness subscales of the PCS were significantly correlated with pain $(r=0.42, \mathrm{P}<0.01$ and $\mathrm{r}=0.25, \mathrm{P}<0.05$, respectively). The BDI and the STAI-T were not significantly correlated with pain. The PCS subscales and the BDI were significantly correlated with perceived disability $(r=0.44$ to 0.55 , $\mathrm{P}<0.05$ ). Pain was also significantly correlated with perceived disability $(\mathrm{r}=0.38, \mathrm{P}<0.05)$.

\section{Predictors of pain and disability}

Separate regression analyses were used to compare the psychological predictors of pain and disability. Table 3 shows the results of a hierarchical regression examining predictors of pain. Age, sex and pain duration were entered in the first step of the analysis but failed to contribute significantly to the prediction of pain $\left(\mathrm{R}^{2}=0.01, \mathrm{~F}[\right.$ change $\left.]=0.3, \mathrm{P}<0.82\right)$. The rumination, magnification and helplessness subscales of the PCS, the BDI and the STAI-T were entered in the second step of the analysis and contributed significantly to the prediction of pain scores $\left(\mathrm{R}^{2}\right.$ [change] $=0.18$, $\mathrm{F}[$ change $]=2.5, \mathrm{P}<0.05)$. Examination of beta weights for the final regression equation revealed that only the magnification subscale of the PCS contributed a significant unique variance to the prediction of pain. The tendency to magnify the threat of pain sensations was associated with heightened pain.
TABLE 4

Hierarchical regression examining psychological predictors of disability in 65 patients referred to a specialty pain clinic with a diagnosis of whiplash injury

\begin{tabular}{|c|c|c|c|c|c|}
\hline Variables & Beta & $\mathbf{R}^{2}$ & F(change) & $P$ & $r$ \\
\hline \multicolumn{6}{|l|}{ Step 1} \\
\hline Age & 0.09 & & & & 0.08 \\
\hline Sex & -0.14 & & & & -0.05 \\
\hline Pain duration & -0.10 & 0.01 & 0.35 & 0.78 & -0.07 \\
\hline \multicolumn{6}{|l|}{ Step 2} \\
\hline Rumin & 0.32 & & & & $0.53^{\star *}$ \\
\hline Magni & 0.05 & & & & $0.43^{* *}$ \\
\hline Helps & 0.09 & & & & $0.51^{* *}$ \\
\hline Depression $^{\dagger}$ & 0.22 & & & & $0.41^{* *}$ \\
\hline Trait-anxiety ${ }^{\ddagger}$ & 0.01 & 0.37 & 6.1 & 0.001 & 0.15 \\
\hline
\end{tabular}

Table 4 shows the results of the hierarchical regression examining predictors of disability. Age, sex and pain duration were entered in the first step of the analysis but did not contribute significant variance $\left(\mathrm{R}^{2}=0.01, \mathrm{~F}\right.$ [change $]=0.35$, $\mathrm{P}<0.78)$. The three subscales of the PCS, the BDI and the STAI-T were entered in the second step of the analysis and contributed significant variance to the prediction of patients' perceived disability ( $\mathrm{R}^{2}[$ change $]=0.37, \mathrm{~F}[$ change $]=6.1$, $\mathrm{P}<0.001$ ). Examination of the beta weights for the final regression equation revealed that none of the predictor variables contributed significant unique variance to the prediction of perceived disability. In a follow-up analysis, pain severity was entered in the second step of a hierarchical analysis, contributing $14 \%$ of the variance in disability ratings, beyond the variance accounted for by age, sex and pain duration ( $\mathrm{F}[$ change $]=9.97, \mathrm{P}<0.01$ ). Psychological variables contributed an additional $27 \%$ of variance to disability ratings, over and above pain severity (F[change $]=5.4, \mathrm{P}<0.001$ ).

\section{DISCUSSION}

The present research showed that, in a sample of patients with whiplash, psychological factors accounted for significant variance in measures of pain and pain-related disability. Together, psychological factors accounted for $18 \%$ of the variance in pain ratings and $37 \%$ of the variance in perceived disability.

The magnification subscale of the PCS contributed significant unique variance to the prediction of pain scores. In other words, patients who endorsed statements such as "I wonder whether something serious may happen" or "I become afraid that the pain will get worse", were particu- 
larly likely to report high levels of pain. Magnification was also significantly correlated with perceived disability.

These findings suggest that the magnification component of catastrophizing may be a risk factor for a heightened pain experience following whiplash injury. Several investigators have suggested that social psychological factors such as modelling and reinforcement may lead individuals to develop catastrophic orientations to their pain experience (9,31). It has been suggested that catastrophizing may develop through experience and may play a causal role in the development of pain and disability following injury $(10,19)$.

It is also possible that the treatment and recovery experience of patients with whiplash may foster the development of magnification in some individuals. For example, a prolonged and slow rate of recovery, as well as the experience of a variety of debilitating symptoms (eg, dizziness, nausea and headaches) may lead some patients to consider the possibility of a serious disorder. Negative results from diagnostic studies may alarm patients to the possibility that the severity of their condition may be dismissed or may go undetected. Divergent opinions expressed by different treating professionals can also contribute to alarmist reactions. In addition, communication from legal council emphasizing the prospect of long term suffering and disability may also promote an exaggerated view of the seriousness of pain symptoms.

Regardless of the origins of magnification in patients with whiplash, once present, magnification appears to exert a negative impact on pain perception. Magnification cognitions may affect the pain experience by focusing the patient's attention on pain sensations or by increasing the emotional distress associated with the pain experience. Magnification cognitions may also exert effects indirectly by contributing to avoidance of physical activity, fostering an excessively cautious approach toward rehabilitation interventions and a fear of reinjury. The net result may be an overprotective passivity, which may contribute further to deconditioning, iatrogenic complications and prolonged disability.

The present findings suggest that interventions specifically targeting magnification cognitions may be useful in facilitating rehabilitation progress in patients with whiplash. Cognitive-behavioural strategies such as reappraisal, re-interpreting or attention diversion may be useful in decreasing the tendency to magnify the threat of pain symptoms (23). In addition to highlighting the consequences of excessively pessimistic interpretations of their pain, patients must be provided with accurate information that will allow them to correct their faulty assumptions about their condition. Patients may benefit from medical information concerning the basis of their pain symptoms and the expected course of recovery. Overly optimistic projections that are at odds with patients' actual experiences or ambiguous information likely serve to maintain the tendency to magnify the threat of pain symptoms. Information that is consistent with patients' experiences and emphasizes the benign nature of their symptoms is likely to be beneficial in reducing magnification.

Research has shown that depressive symptoms occur with a high frequency in individuals suffering from chronic pain (43-45). Consistent with previous research, the present study revealed that $66 \%$ of patients with whiplash scored within the clinical range on the BDI. Previous research has shown depressive symptoms to be correlated with ratings of pain intensity $(9,10,42)$. In the present study, depression scores were correlated with perceived disability but not ratings of pain intensity. It is possible that the absence of a direct relation between pain and depression may be due to a variety of sample-specific variables. In the first year after injury, individuals are likely to be faced with several stressful life changes that are only indirectly linked to pain severity. For example, the patient with whiplash experiences the stress of multiple medical investigations, prognostic uncertainty, the financial stresses of unemployment, increased interpersonal dependence, and strained social and familial roles. The cumulative effect of these stresses may heighten the probability of experiencing depressive symptoms, regardless of the actual severity of the pain symptoms $(46,47)$. Because emotional distress tends to be most apparent in the time period proximal to the stressor, the effects of the many life stresses faced by patients with whiplash may dissipate with time. In patients with more long term pain, a relation between pain and depression may emerge as the effects of other life stresses diminish (42).

In the present study, depression was significantly correlated with ratings of perceived disability. This finding is consistent with findings of previous studies showing that depression may compromise progress in rehabilitation $(45,48)$. The associated features of depression, such as feelings of hopelessness, pessimism about the future and reduced motivation, may contribute to patients' heightened perceptions of disability.

Several clinicians and researchers have highlighted the importance of early intervention in facilitating recovery from pain-related injuries $(7,26,49)$. The present findings extend previous work in suggesting that early interventions that target magnification cognitions and depression may avert the development of high levels of pain and disability. Screening patients on measures of catastrophizing and depression following whiplash injury may help to identify patients who could benefit from intervention.

Psychological variables accounted for twice the variance in disability ratings compared with pain ratings. Thus, while psychological variables are significant determinants of the pain experience, they may be even more important in accounting for disability. Indeed, in the present sample, psychological variables were more important determinants of disability than pain itself. These findings have implications for rehabilitation approaches to the management of whiplash symptoms. Essentially, they suggest that rehabilitation approaches that focus primarily on pain reduction may not yield satisfactory outcomes. Reducing catastrophic 
thinking and depressive symptomatology may be as important as reducing pain in fostering functional recovery following whiplash injury.

Both anecdotal and empirical studies have pointed to the significant role of litigation in accounting for pain and disability in those who suffer from persistent pain (22). Albeit significant, litigation is likely to be only one component of a host of factors that may influence the expression of pain and disability following whiplash injury. It is clear that, despite litigation involvement, the majority of individuals who sustain whiplash injuries do not remain disabled (7). The present sample consisted only of individuals involved in litigation, and psychological factors still accounted for significant variance in pain and disability ratings. Thus, it is important to look beyond litigation issues to understand fully the factors that contribute to pain and disability following whiplash injury.

Caution must be exercised in the interpretation of current findings. First, the sample was drawn from a specialty pain clinic, and referral biases may have influenced the nature of the physical and psychological characteristics observed in patients. Given that patients were experiencing high levels of pain and disability more than eight months after injury, they represent the subsample (and minority) of patients with whiplash who do not have a timely recovery following injury. The cross-sectional design of the research also has inherent limitations, primarily with respect to assigning causal priority to specific variables. Greater certainty in the role of catastrophizing and depression in predicting pain and disability following whiplash must await replication within a prospective design.

ACKNOWLEDGEMENTS: This research was supported by grants from the Social Sciences Research Council of Canada, Dalhousie University, the Canadian Institutes of Health Research and the Atlantic Pain Clinic. The authors thank Heather Thomas and Karen Rideout for their assistance with data entry.

\section{REFERENCES}

1. Robinson DD, Cassar-Pullicino VN. Acute neck sprain after road traffic accident: a long term clinical and radiological review. Injury 1993;24:79-82.

2. Croft AC. Low speed rear impact collisions: in search of an injury threshold. In: Allen ME, ed. Musculoskeletal Pain Emanating from the Head and Neck: Current Concepts in Diagnosis, Management and Cost Containment. London: Haworth Medical Press, 1996:39-46.

3. Norrris SH, Watt I. The prognosis of neck injuries resulting from rearend vehicle collisions. J Bone Joint Surg Br 1983;65:608-11.

4. Ebbs SR, Beckly DE, Hammonds JC, Teasdale C. Incidence and duration of neck pain among patients injured in car accidents. Br Med J 1986;292:94-5.

5. Barnsley L, Lord S, Bogduk N. Whiplash injury. Pain 1994;58:283-307.

6. Radanov BP, Sturzenegger M, Di Stephano G. Long-term outcome after whiplash injury. A 2-year follow-up considering features of injury mechanism and somatic, radiologic, and psychosocial findings. Medicine (Baltimore) 1995;74:281-97.

7. Spitzer WO, Skovron ML, Salmi LR, et al. Scientific monograph of the Quebec task force on whiplash associated disorders: redefining "whiplash" and its management. Spine 1995;20(8 Suppl):1S-73S.

8. Radanov BP, Sturzenegger M. The effect of accident mechanisms and initial findings on the long term outcome of whiplash injury. J Musculoskelet Pain 1996;4:47-59.
9. Rosenstiel AK, Keefe FJ. The use of coping strategies in chronic low back pain patients: relationship to patient characteristics and current adjustment. Pain 1983;17:33-44.

10. Keefe FJ, Brown GK, Wallston KA, Caldwell DS. Coping with rheumatoid arthritis: catastrophizing as a maladaptive strategy. Pain 1989;37:51-6.

11. Martin YM, Bradley LA, Alexander RW, et al. Coping strategies predict disability in patients with primary fibromyalgia. Pain 1996;68:45-53.

12. Bedard GB, Reid GJ, McGrath PJ, Chambers CT. Coping and self-medication in a community sample of junior high school students. Pain Res Manage 1997;2:151-6.

13. Fields H. Depression and pain: a neurobiological model. Neuropsychiatry Neuropsychol Behav Neurol 1991;4:83-92.

14. Magni G, Moreshi C, Rigatti-Luchini S, Merskey H. Prospective study on the relationship between depressive symptoms and chronic musculoskeletal pain. Pain 1994;56:289-97.

15. Banks SM, Kerns RD. Explaining high rates of depression in chronic pain: a diathesis-stress framework. Psychol Bull 1996;119:95-110.

16. Jensen MP, Turner JA, Romano JM, Karoly P. Coping with chronic pain: a critical review. Pain 1991;47:249-83.

17. Lackner JM, Carosella AM, Feuerstein M. Pain expectancies, pain, and functional self-efficacy expectancies as determinants of disability in patients with chronic low back disorders. J Consult Clin Psychol $1996 ; 64: 212-20$

18. Keefe FJ, Alleck G, Lefebvre JC, Starr K, Caldwell H, Tennen H. Pain coping strategies and coping efficacy in rheumatoid arthritis: a daily process analysis. Pain 1997;69:27-34.

19. Sullivan MJL, Stanish W, Waite H, Sullivan M, Tripp DA. Catastrophizing, pain, and disability in patients with soft tissue injuries. Pain 1998;77:253-60.

20. Weintraub MI. Regional pain is usually hysterical. Arch Neurol 1988;44:914-5.

21. Ferrari R, Russell AS. The whiplash syndrome - common sense revisited. J Rheumatol 1997;24:618-22.

22. Rainville J, Sobel JB, Hartigan C, Wright A. The effect of compensation involvement on the reporting of pain and disability by patients referred for rehabilitation of chronic low back pain. Spine 1997;26:2016-24.

23. Turk DC, Meichenbaum D, Genest M. Pain and Behavioral Medicine: A Cognitive-Behavioral Perspective. New York: Guilford, 1983.

24. Rudy TE, Kerns RD, Turk DC. Chronic pain and depression: toward a cognitive-behavioral mediation model. Pain 1988;35:129-40.

25. Wallis BJ, Lord SM, Bogduk N. Resolution of psychological distress of whiplash patients following treatment by radiofrequency neurotomy: a randomized, double-blind, placebo-controlled trial. Pain 1997;73:15-22

26. Fordyce WE. On the nature of illness and disability: an editorial. Clin Orthop 1997;336:47-51.

27. McCracken LM, Zayfert C, Gross RT. The Pain Anxiety Scale: Development and validation of a scale to measure fear of pain. Pain 1992;50:67-73.

28. Craig K. Emotional aspects of pain. In: Melzack R, Wall P, eds. Textbook of Pain. New York: Churchill Livingstone, 1989:220-30.

29. Keefe JF, Gil KM. Behavioural concepts in the analysis of chronic pain syndromes. J Consult Clin Psychol 1986;54:776-83.

30. McCracken LM, Gross RT. Does anxiety affect coping with pain? Clin J Pain 1993;9:253-9.

31. Sullivan MJL, Bishop S, Pivik J. The Pain Catastrophizing Scale: development and validation. Psychol Assess 1995;7:524-32.

32. Sullivan MJL, Tripp D, Santor D. Gender differences in pain and pain behaviour: the role of catastrophizing. Cogn Ther Res. (In press)

33. Beck AT, Ward CH, Mendelson M, Mock J, Erbaugh J. An inventory for measuring depression. Arch Gen Psychiatry 1961;4:561-71.

34. Beck AT, Steer RA, Garbin MG. Psychometric properties of the Beck Depression Inventory: twenty five year evaluation. Clin Psychol Rev 1988;1:77-100.

35. Bishop SR, Edgley K, Fisher R, Sullivan MJL. Screening for depression in chronic low back pain with the Beck Depression Inventory. Can J Rehabil 1993;7:143-8.

36. Spielberger CD, Gorsuch RL, Lushene RE. STAI: Manual for the State-Trait Anxiety Inventory. Palo Alto: Consulting Psychologists Press, 1970. 
37. Melzack R. The McGill Pain Questionnaire: major properties and scoring methods. Pain 1975;1:277-99.

38. Turk DC, Rudy TE, Salovey P. The McGill Pain Questionnaire reconsidered: confirming the factor analysis and examining appropriate uses. Pain 1985;21:385-97.

39. Pollard CA. Preliminary validity study of the Pain Disability Index. Percept Mot Skills 1984;59:974

40. Tait RC, Chibnall JT, Krause S. The Pain Disability Index psychometric properties. Pain 1990;40:171-82.

41. Tait RC, Pollard CA, Margolis RB, Duckro PN, Krause SJ. The Pain Disability Index: psychometric and validity data. Arch Phys Med Rehabil 1987;68:438-41.

42. Sullivan MJL, D'Eon J. Relation between catastrophizing and depression in chronic pain patients. J Abnorm Psychol 1990;99:260-3.

43. Magni G, Caldieron C, Rigatti-Luchini S, Merskey H. Chronic musculoskeletal pain and depressive symptoms in the general population: an analysis of the 1st National Health and Nutrition Examination Survey data. Pain 1990;43:299-307.

44. Dworkin RH, Gitlin MJ. Clinical aspects of depression in chronic pain patients. Clin J Pain 1991;7:79-94.

45. Sullivan MJL, Reesor K, Mikail S, Fisher R. The treatment of depression in chronic low back pain: review and recommendations, Pain 1992;50:5-13.

46. Lazarus RA, Folkman S. Stress, Appraisal, and Coping. New York: Springer, 1984.

47. Folkman S, Lazarus RS. Stress process and depressive symptomatology. J Abnorm Psychol 1986;95:107-33.

48. Kerns RD, Haythornthwaite JA. Depression among chronic pain patients: cognitive behavioral analysis and effect on rehabilitation outcome. J Consult Clin Psychol 1988;56:870-6.

49. Fordyce WE, ed. Back Pain in the Workplace. Seattle: IASP Press, 1995. 


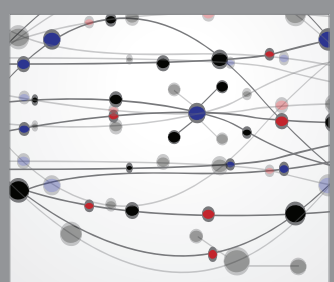

The Scientific World Journal
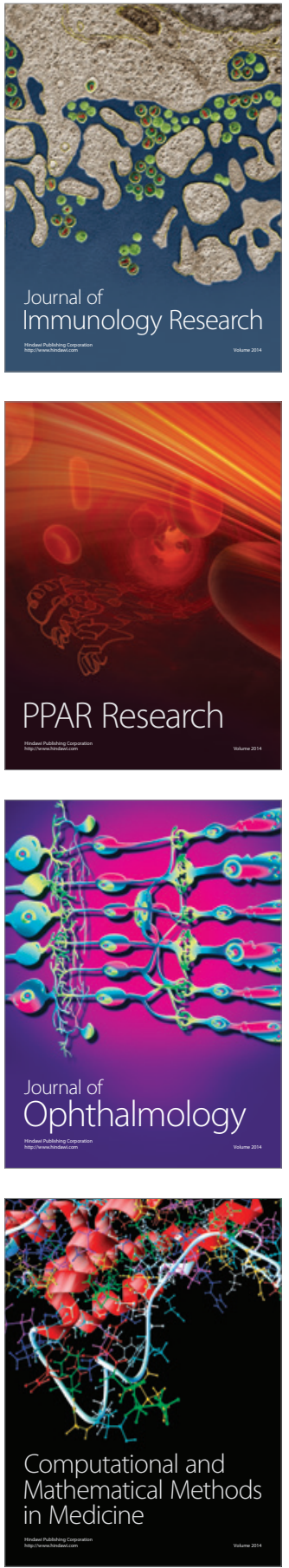

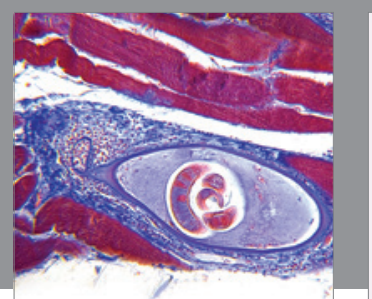

Gastroenterology Research and Practice

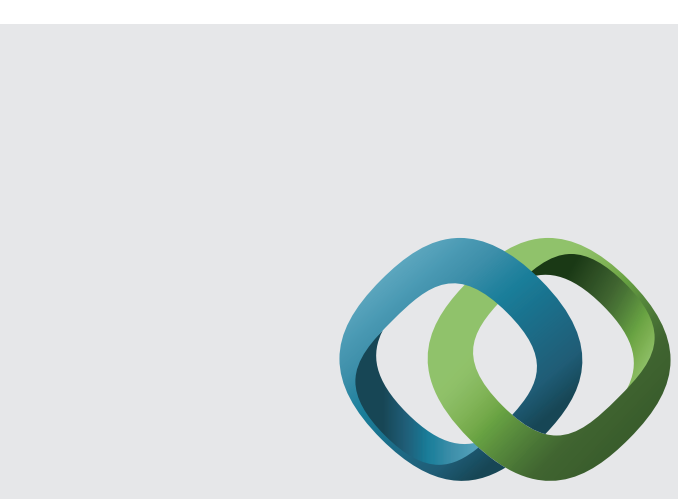

\section{Hindawi}

Submit your manuscripts at

http://www.hindawi.com
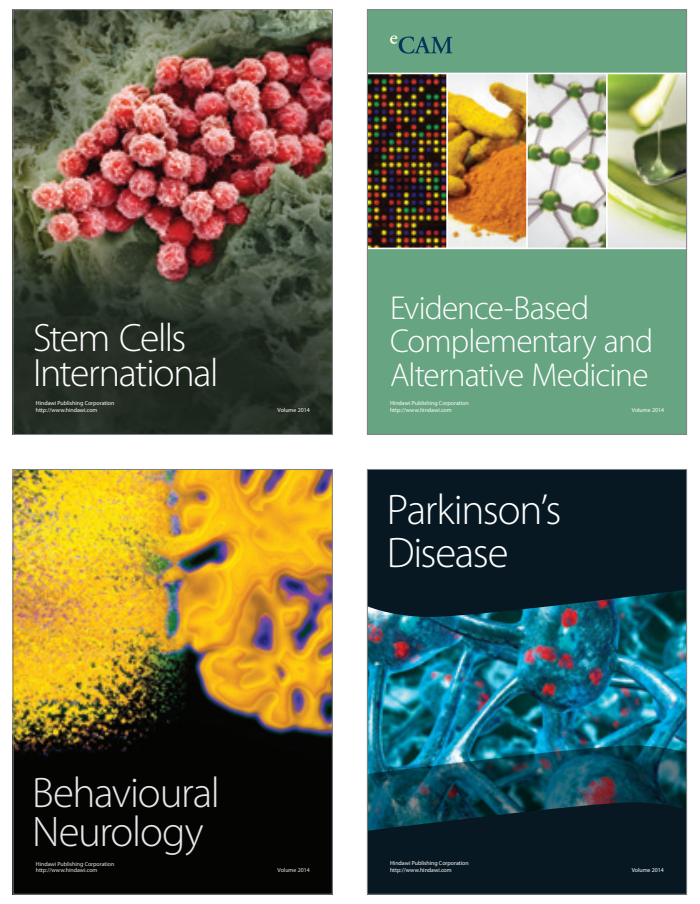
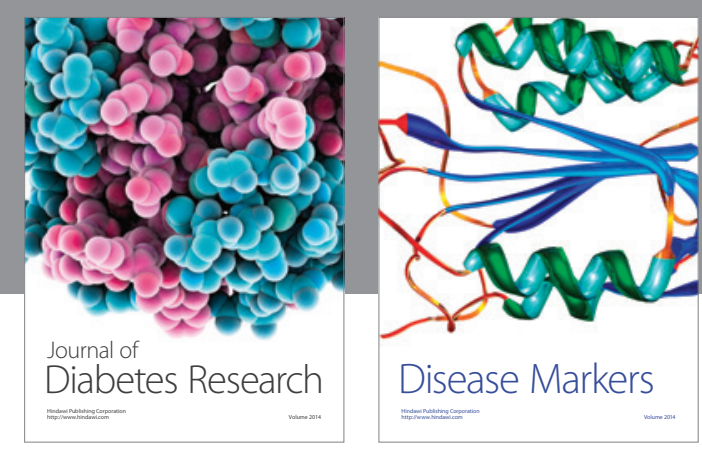

Disease Markers
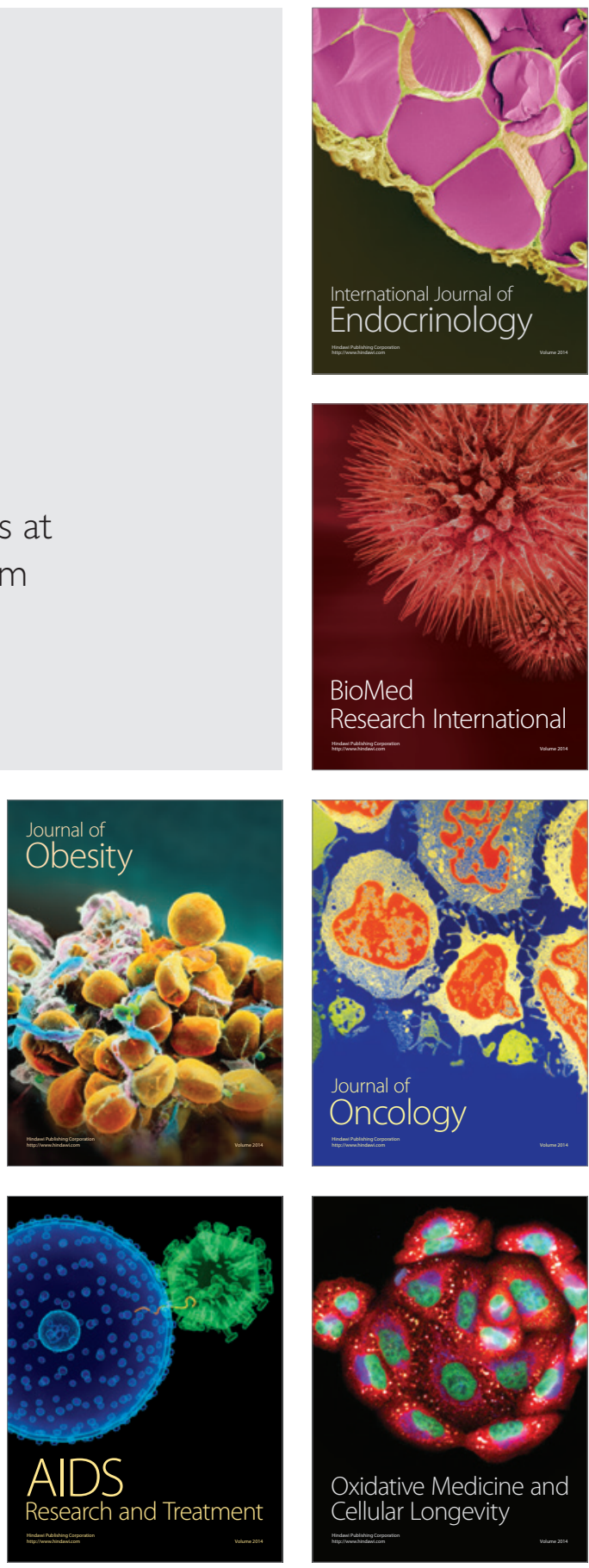